\title{
Piotr Rutkowski
}

http://orcid.org/0000-0001-7963-2948

Uniwersytet Warszawski

Jacek Ziółkowski

http://orcid.org/0000-0003-3349-5188

Uniwersytet Warszawski

\section{Neuropolityka - geneza, założenia, perspektywy rozwoju}

\section{Neuropolitics - Genesis, Assumptions, Development Prospects}

\begin{abstract}
Neuropolitcs is an interdisciplinary research area, located at the intersection of various sciences, combining political science with neuroscience. However, it is not another direction that, as it may seem assumes biological determinism. It is based on belief about the interfusion of nature and culture, physical and mental dimensions in man. The aim of article is to familiarize the reader with the historical and theoretical aspects of this still developing research area. Also the research tools and main research directions of neuropolics were outlined. Authors indicate the positive and negative results of neuropolitics research and perspectives for political science and neurosciences.
\end{abstract}

Keywords: neuropolitcs, political science, social neuroscience, biopolitics, nature, culture, biology

Celem poniższego artykułu jest przybliżenie zmian, jakie niesie dla badań politologicznych rozwój współczesnych neuronauk społecznych. W ciągu ostatnich dekad zmiany w zakresie narzędzi badawczych stworzyły warunki do kolejnej odsłony realizacji badań biopolitycznych. W tym przypadku odbywa się to m.in. pod sztandarem neuronauki.

Historia rozważań nad anatomią, fizjologią i funkcjami ludzkiego mózgu sięga czasów antycznych. Przez ostatnie dwa stulecia, cyklicznie, można było obserwować wzrost zainteresowania i nadziei związanych $\mathrm{z}$ badaniem ludzkiego mózgu: jego budowy, fizjologii, funkcji poszczególnych części. Sam tylko europejski projekt HBP (The Human Brain Project), rozpoczęty w 2013 roku, finansowany przez Unię Europejską i nastawiony m.in. na próbę przybliżenia 
neurofizjologicznych podstaw umysłu ludzkiego, zyskał finansowanie ok. 1,5 mld euro. Podobne w założeniach projekty są realizowane m.in. w Szwajcarii, Japonii, USA czy Chinach.

Próba odpowiedzi na pytania o powiązania mózgu jako struktury anatomiczno-fizjologicznej i umysłu jako struktury poznawczej, motywacyjnej i decyzyjnej przeżywała liczne wzloty i upadki. Ostatnie trzy dekady to bardzo dynamiczny i integracyjny rozwój neurofizjologii, psychiatrii, psychologii klinicznej i społecznej, kognitywistyki. Związane jest to w znacznej mierze nie tylko ze zmianami podejść w badaniach społecznych, lecz także z doskonaleniem metod i narzędzi badawczych. Rodzina neuronauk pojawia się na polach przedmiotowych wcześniej nieoglądanych. Przenika do sfery filozofii, ekonomii, zarządzania, prawoznawstwa, marketingu, a także na pole nauk o polityce.

W zamierzeniu autorów tekst ten ma na celu nie tylko przybliżenie podstawowych założeń i metod badawczych neuronauki społecznej, lecz co ważniejsze - prześledzenie miejsca neuronauki w naukach o polityce i badań politologicznych $\mathrm{w}$ dotychczasowych badaniach neuronauk społecznych. Mowa tu zatem o neuropolityce (neuropolitics) lub - jak chcą inni - politycznej neuronauce (political neuroscience) (por. Connolly, 2002). Wiele współczesnych badań z tego zakresu wkracza na typowe pola zainteresowań politologów. Badane tu są np.: neurofizjologiczne podstawy orientacji ideologicznych, preferencji partyjnych, aktywności politycznej, decyzji politycznych, postaw politycznych, skłonności do stosowania agresji i wielu innych. To klasyczne pola zainteresowania psychologii polityki i samych „rasowych” politologów. Nie można pominąć dynamicznie rosnącego woluminu konferencji, artykułów, monografii z zakresu neuropolityki, neurowładzy, neuromarketingu itp. Taki trend stanowi istotne wyzwanie dla politologów o zapleczu dotychczasowych metod empirycznych, a tym bardziej tych usposobionych do refleksji humanistycznej. Tu istotna jest odpowiedź na pytania: czy neuronauka w istotny sposób przyczynia się do rozwoju wiedzy o polityce? Jeśli tak, to $\mathrm{w}$ jakim zakresie? Czy i w jakim zakresie jest tu miejsce dla samych politologów? Jakie są w końcu nadzieje, a jakie granice neuronauki w zakresie pola przedmiotowego nauk o polityce? Autorzy stawiają tu tezę zakładającą ostrożny optymizm wobec przyszłości tego podejścia badawczego. O ile teza o rewolucji i zastąpieniu przez badania neurofizjologiczne szerszego spektrum badań politologicznych wydaje się, jak na razie, przedwczesna, o tyle brak uwzględnienia tej perspektywy przez politologów ogranicza zakres przedmiotowy i narzędziowy współczesnych badań nad polityką.

Tak postawione pytania determinują strukturę artykułu, w którym zostaną omówione: umiejscowienie neuropolityki w spektrum współczesnych neuronauk społecznych, historyczne i teoretyczne podwaliny rozwoju neuropolityki, główne kierunki współczesnych badań z tego zakresu, analiza aparatu narzędziowego oraz nakreślenie perspektyw rozwoju dla subdyscypliny neuropolityki. Warto nadmienić, że nie sposób całościowo nakreślić historii, rozwoju, 
podstaw teoretycznych oraz narzędzi neuropolityki. Autorzy jedynie przedstawiają główne założenia i elementy neuropolityki, których obecność w polskiej myśli politologicznej jest jak dotychczas wyjątkowo uboga.

\section{Geneza podejścia neuropolitycznego}

Naturalnym źródłem badań neuropolitycznych jest rozwój interdyscyplinarnego obszaru wiedzy, jakim są neuronauki (w tym neuronauki społeczne). Ich powstanie, które datuje się na lata 60. XX wieku, wiąże się ściśle z kolejnymi dokonaniami i postępem wiedzy (oraz aparatury badawczej) w zakresie ludzkiego mózgu. Zainteresowanie tym organem rozpoczęło się jednak jeszcze wcześniej - od badań nad ludzkimi czaszkami i prób rozpoznania w ich właściwościach powodów różnych cech człowieka. Następnie, już w XX wieku, postęp wiedzy umożliwił dostrzeżenie procesów biofizycznych, chemicznych oraz elektrycznych, które odbywały się w ludzkim mózgu. Wówczas rozpoczął się w USA etap rozwoju neurofarmakologii, kiedy to powszechnie przepisywano różnego rodzaju środki, np. antydepresyjne. Wraz z wynalezieniem tomografii komputerowej oraz rezonansu magnetycznego mózg stał się czymś realnym. Nie był już wiązką reakcji chemicznych i elektrycznych, lecz stał się ontologicznie realny, nawet jeśli wyniki badań były jedynie obrazem jego struktury. Kolejny postęp technologiczny w postaci pozytonowej tomografii emisyjnej oraz funkcjonalnego rezonansu magnetycznego umożliwił bardziej pogłębione badania. Aktywność mózgu mogła być obserwowana podczas wykonywania różnego rodzaju czynności. Dało to ogromne pole do wielu badań nad funkcjonowaniem mózgu człowieka i możliwość podjęcia próby pełnego poznania tajemnicy „czarnej skrzynki”, niegdyś zupełnie pomijanej jako niedostępnej (Rose, Abi-Rached, 2014, s. 7-13). Jednakże prawdziwym przełomem w rozwoju neuronauk była koncepcja plastyczności neuronalnej. Dostrzeżono, że mózg nie jest statycznym organem, który od urodzenia aż do śmierci człowieka zachowuje tę samą anatomię i każdy z jego elementów pełni tę samą funkcję, lecz w pełni adaptuje się do środowiska, zmienia wraz z czynnościami wykonywanymi przez człowieka przez pewien czas. Otworzyło to kolejne możliwości badania mózgu, od tego momentu już w określonym kontekście, i wzbudziło ostrożność dotyczącą uogólniania badań na całą populację (Jost et al., 2014, s. 29-30). Był to również impuls dla zorientowanych społecznie badaczy do zastosowania narzędzi wypracowanych $\mathrm{w}$ ramach neuronauk do badania zjawisk społecznych, co dało początek zarówno neuronaukom społecznym, jak i neuropolityce, „neuropolitologii” (Lemke, 2010, s. 23) ${ }^{1}$ czy neuronaukom politycznym.

Thomas Lemke w swej publikacji przetłumaczył wyraz „biopolitics” jako „biopolitologia”, stąd analogicznie „neuropolitologia”. W tekście jednak dominować będzie tłumaczenie „neuropolitics” jako „neuropolityka”. 
Jako punkt zwrotny, a zarazem początkowy w rozwoju neuronauk społecznych wskazuje się badania Antonia Damasia nad pacjentami, którzy doznali uszkodzenia konkretnych części mózgu (Damasio, 1994). Najgłośniejszy był jednak powrót do sprawy Phineasa Gage’a z 1848 roku, który w wyniku wypadku doznał uszkodzenia prawej i lewej kory przedczołowej. Taka diagnoza, postawiona przez Damasia, była możliwa dzięki przeanalizowaniu oraz komputerowemu odtworzeniu czaszki Gage’a (która była dobrze zachowana) oraz naniesieniu uszkodzenia na obraz mózgu. Przypadek był o tyle ciekawy, że po zdarzeniu Gage zmienił się w „,innego człowieka”. Z „(...) odpowiedzialnej, inteligentnej, dobrze przystosowanej społecznie jednostki (...)" (Damasio, Damasio, Frank, Grabowski, Galaburda, 2005, s. 22) stał się osobą łamiącą normy społeczne, nieodpowiedzialną i niegodną zaufania, pojawiły się problemy z podejmowaniem decyzji. $Z$ kolei jego cechy i funkcje biologiczne pozostały niezmienne. Analiza przypadku Phineasa Gagea oraz kolejnych mu podobnych (Damasio, 1994, s. 34-62; Anderson, Bechara, Damasio, Damasio, Tranel, 2005) pozwoliła na wyciągnięcie dwóch istotnych dla neuronauk społecznych wniosków:

- odrzucenie kartezjańskiego dualizmu - badania przeprowadzone przez Damasia i innych wykazały, że dualizm duszy i ciała, zaproponowany niegdyś przez Kartezjusza, jest fikcją. Te same ośrodki w mózgu człowieka, które odpowiadają za działania oraz decydowanie o charakterze racjonalnym, są odpowiedzialne również za emocje. Nie można zatem oddzielić poznania opartego na emocjach od racjonalnego;

- z powyższego wniosku utworzono hipotezę markerów somatycznych, czyli mechanizmu w organizmie człowieka, który w relacji między biologią a otoczeniem (czyli w wyniku m.in. doświadczeń, kultury itd.) nieświadomie (np. poprzez emocje) w procesie decydowania odrzuca rozwiązania niekorzystne dla jednostki. Ta $\mathrm{z}$ kolei dokonuje rozumowego wyboru wśród już ograniczonych alternatyw.

Doprowadziło to również do kolejnego etapu w dyskusji nad problemem między naturą a kulturą oraz potrzebą badań interdyscyplinarnych. Pełne poznanie człowieka wymaga zarówno badań o charakterze biologicznym, jak i uwzględnienia czynników społeczno-kulturowych. Szczególnie w poznaniu istoty człowieka nie jest możliwe oddzielenie tych dwóch elementów od siebie, co więcej, problem jest w powyższym świetle pozorny.

$\mathrm{Za}$ istotne wydarzenie, ukazujące rosnącą rolę neuronauki społecznej, wskazuje się organizację międzynarodowej konferencji naukowej Social Cognitive Neuroscience Conference w 2001 roku, która cieszyła się ogromnym zainteresowaniem wśród naukowców z różnych dyscyplin na całym świecie (Schreiber, 2017, s. 117-118). Jak zauważają John Cacioppo i Gary Berntson: „Neuronauki społeczne powstały zatem, by odnieść się do fundamentalnych pytań o umysł i jego dynamiczne interakcje $z$ biologicznymi systemami mózgu i ciała oraz społecznym światem, w którym rezyduje. Interesuje je relacja między neuronalnymi 
i społecznymi procesami (...)" (Cacioppo, Berntson, 2005, s. XII, tłum. P.R.). Z kolei ważnym wydarzeniem dla neuropolityki był specjalny numer czasopisma „Political Psychology”, poświęcony relacjom i współpracy między neuronaukami a naukami o polityce (Schreiber, 2017, s. 118-119).

\section{Neuropolityka a rozwój neuronauk społecznych - spektrum neuronauk}

Współczesna neuropolityka jest tylko jedną z wielu subdyscyplin neuronauk. Łączy je ogólne podejście, zainteresowanie układem nerwowym człowieka (jego budową, funkcjonowaniem, wpływem na stany psychiczne itp.) na wielu poziomach: od poziomu nanoneuronowego do poziomu złożonych połączeń funkcjonalnych między mózgiem a umysłem. Trzeba mieć także świadomość, iż współcześnie podejście to znajduje swoje miejsce niemalże we wszystkich ważniejszych dyscyplinach naukowych. W tym zakresie badania prowadzi np.: behawioralna neuronauka, emocjonalna neuronauka, kulturowa neuronauka, informatyczna neuronauka, poznawcza neuronauka, społeczna neuronauka, lecz także np.: neurolingwistyka, neuroekonomia, neurogenetyka, neurofilozofia i wiele innych. Tym, co je łączy, jest próba wyjaśnienia typowych problemów badawczych z perspektywy analiz na poziomie układu nerwowego, morfologii, fizjologii mózgu, biochemii procesów zachodzących w ramach złożonych i wielopoziomowych struktur układu nerwowego. W takim ujęciu dotychczasowe pytania uzyskują nowy wymiar badań, opisu, wyjaśnienia, predykcji. W takim też kontekście należy systematyzować oraz postrzegać neuropolitykę. Takie neurobiologiczne podejście do badania zjawisk politycznych realizuje dwa główne cele naukowe:

- funkcje poznawcze, gdzie tradycyjne problemy politologiczne są analizowane przez pryzmat płaszczyzny neurobiologicznej (np.: różnice anatomiczne osób o określonych orientacjach ideologicznych, uaktywnienie określonych części mózgu przy podejmowaniu decyzji politycznych itp.);

- funkcje utylitarne, gdzie badania neurobiologiczne są wykorzystywane w zakresie dostarczania wiedzy praktycznej (np.: w zakresie propagandy politycznej, marketingu politycznego itp.).

W pierwszym przypadku celem badań jest lepsze zrozumienie neurobiologicznej bazy postaw politycznych, dookreślenie charakteru przeżyć politycznych, określenie motywatorów orientacji i zachowań politycznych. W drugim przypadku podejmowane są próby wykorzystania podstawowych badań z zakresu neuronauki do działań z zakresu praktyki politycznej.

Teoretyczne aspekty badań z zakresu neuropolityki pochodzą wprost z neuronauk społecznych, które posiadają określone ontologiczne i epistemologiczne założenia. Pierwsze z nich zakładają, że: 
- wszystkie procesy umysłowe są zdarzeniami, które swe podłoże mają w mózgu - jest to organ, który w swej istocie scala wszystkie funkcje człowieka i steruje całym organizmem. Nie jest zatem istotne, czy kwestią są procesy biologiczne czy społeczne, mózg jako system otrzymywania, przetwarzania i wysyłania informacji pełni w nich centralną funkcję;

- mózg charakteryzuje się plastycznością. Oznacza to, że w zależności od kultury, w jakiej jednostka funkcjonuje i została wychowana, osobistych doświadczeń czy codziennych przyzwyczajeń oraz czynności, jego struktura i funkcje mogą się różnić. Mózg nie jest zatem statyczny, lecz stale dokonuje się wymiana informacji z otoczeniem, środowiskiem i adaptacja do wymagań świata zewnętrznego. Społeczeństwo, w którym jednostka istnieje, ma zatem o wiele większy i głębszy wpływ na jej funkcjonowanie niż tylko na poziomie świadomości i umysłu. George Lakoff wskazuje, że nieświadome myślenie i automatyzmy to $98 \%$ myślenia człowieka (Lakoff, 2009, s. 9). Są to właśnie te procesy, które funkcjonują poprzez to, że ogólnie rozumiane środowisko (kultura, tradycja, religia, doświadczenia społeczne itd.) wpłynęło na umysł (płaszczyznę psychiczną) człowieka, a poprzez to na jego mózg (płaszczyznę biologiczną) (Altermark, Nyberg, 2018, s. 39-41). Robert Blank ujął to wprost, pisząc, że wszelkie różnice, jakie występują na poziomie systemów kulturowych, mają swe odniesienie do różnic w systemach mózgu (Blank, 2013, s. 165-169).

W zakresie epistemologicznym Niklas Altermark i Linda Nyberg podkreślają, że neuronauki są bliskie podejściom pozytywistycznym. Mimo uznania założenia o kulturowym wpływie na mózg te elementy nie odgrywają żadnej roli w badaniach z zakresu neuropolityki (Altermark, Nyberg, 2018, s. 39-43). Autorzy dostrzegają, że narzędzia oferowane przez neuronauki stoją na równi z metodami ilościowymi, które zostały uznane za obiektywne pomiary rzeczywistości społeczno-politycznej, umożliwiające wyalienowanie (w sensie naukowym) badacza od przedmiotu badania, a zatem spojrzenie z dystansu, z pominięciem wszelkiej historii zjawisk, ideologii czy społecznych przyczyn problemów, uprzedmiotowienia. Próbują odnaleźć i zidentyfikować ośrodek biologiczny odpowiadający za dane zjawisko społeczne, co przybliża do behawioralizmu, którego głównym motywem są relacje bodziec-reakcja.

$\mathrm{Z}$ drugiej jednak strony czołowi przedstawiciele neuronauk społecznych John Cacioppo i Penny Visser wskazują, że w badaniach z tego zakresu trzeba kierować się dużą ostrożnością w ocenach dotyczących łączenia konkretnego elementu mózgu z danym zjawiskiem czy procesem, a przez to uogólniania wyników badań na szersze grupy. Argumentem jest plastyczność, przez którą mózg w różny sposób adaptuje się do rzeczywistości społecznej i indywidualnych cech jednostki, a przez to różne jego części mogą pełnić różne funkcje u innych ludzi (Cacioppo, Visser, 2003; Por. Schreiber, 2011, s. 273-275). Autorzy ci wyróżnili również istotne z perspektywy neuronauk społecznych założenia i zasady, którymi powinni kierować się badacze: 
- zwrócenie uwagi na poziom analizy - neuronauki i nauki społeczne ze względu na specyfikę swojego przedmiotu zajmują się zjawiskami, które mają swe źródła oraz reprezentacje jednocześnie na różnych poziomach analizy - od jednostkowego, przez grupowy, społeczny, po wręcz globalny. Stanowi to ogromne wyzwanie. Pełne poznanie fenomenu z tego zakresu wymaga interdyscyplinarnej analizy i danych - od biologicznych (człowieka jako istoty biologicznej) po kulturowe (człowieka jako istoty kulturowej). Neuronauka nie jest ukazana jako jedyne obiektywne źródło wiedzy, lecz element, z którego może zostać zbudowany pełniejszy obraz zjawiska;

- wielość determinant - fenomeny, szczególnie te społeczne, nie posiadają jednej przyczyny. Działania człowieka mają zazwyczaj zarówno wyjaśnienie biologiczne (przystosowanie ewolucyjne, popędy, potrzeby biologiczne organizmu), jak i kulturowe, które nierzadko potrafi modyfikować to pierwsze (odrzucenie konkretnych potraw czy sam wstyd). Neuronauki pełnią tutaj funkcję uzupełniającą o kolejne możliwe wyjaśnienia i determinanty, które składają się na całość wiedzy człowieka o nim samym. Nie tworzą jedynej obiektywnej wiedzy;

- nieaddytywny determinizm - oznacza, że pewne właściwości, które posiada całość, nie mogą być wywiedzione z cech poszczególnych części. Zasada ta, postulowana przez Cacioppa i Visser, wynika $\mathrm{z}$ faktu różnicy w rezultatach badań dokonywanych na poszczególnych jednostkach oraz tych umieszczonych w społecznym kontekście. Nie może być zatem mowy o przypisywaniu poszczególnych wyników neuronauk społecznych całości, o ile nie przekraczają one pewnego poziomu analizy - w tym przypadku jednostkowego, psychologicznego.

- wzajemny determinizm - oznacza, że zarówno to, co obecne na poziomie biologicznym, jak i społecznym wzajemnie wpływa na siebie w zakresie procesów mózgowych i zachowania się jednostek. W neuronaukach spolecznych, w tym neuropolityce, nie ma zatem jednokierunkowych relacji, wspomniane obydwa poziomy modyfikują się wzajemnie (Cacioppo, Visser, 2003, s. 648-654).

\section{Neuropolityka jako podejście biopolityczne - integracja badań nad polityką}

Badania o charakterze neuropolitycznym mogłyby być posądzone o determinizm biologiczny. Jak wynika z poprzednich rozważań, neuropolityka, jak i neuronauki społeczne takich założeń nie zawierają. Co więcej, wydaje się, że głównym zadaniem, które stawiają sobie badacze, jest poszerzenie wiedzy w zakresie człowieka, 
jego mózgu i umysłu (np. neuronauki kognitywne), prowadzenie interdyscyplinarnych badań i współpraca $\mathrm{z}$ dyscyplinami zainteresowanymi istotą ludzką po to, by uzyskać jak najszerszą i możliwie najpełniejszą wiedzę. U źródeł badań biopolitycznych - nie w rozumieniu biopolityki Michela Foucaulta, lecz biologicznych aspektów polityki - leżało przekonanie o potrzebie kooperacji między naukami przyrodniczymi, społecznymi i humanistycznymi oraz odrzucenia sztywnych granic, które z różnych względów dzielą dyscypliny. W ostatniej dekadzie XX wieku Roger Masters podjął próbę zasypania podziałów, które występowały w dyskusjach wokół problemu natury i kultury. Pytanie, które stawia, brzmi: czy w naukach społecznych, czy innych zajmujących się człowiekiem (jako indywidualnym bytem, jego funkcjonowaniem w grupie lub większych całościach), można oddzielić człowieka od jego biologii lub od jego kultury? Zapomnieć, że świadomość i umysł są wytworem kultury lub że istota ludzka zawsze jest organizmem biologicznym? Według Mastersa trop integracji świata biologicznego i społecznego prowadzi już od Arystotelesowskiego zoon politikon - zwierzęcia, a więc organizmu, którego naturą jest życie w społeczeństwie i kulturze (Masters, 1989, s. 130-132). Wskazał on również na pięć bardzo istotnych postulatów, które dotyczą integracji badań biologicznych i społecznych:

- rozwaga przy określaniu, czy dane zjawisko ma charakter biologiczny czy społeczny;

- generalizacja wyników badań przeprowadzonych na jednostkach lub mniejszych grupach powinna następować dopiero poprzez przeniesienie ich na wyższy poziom, który umożliwi umieszczenie ich w kontekście całości;

- zjawiska, procesy powinny być przedstawiane w szerszym kontekście, a ich przyczyny niesprowadzane jedynie do fizycznych, obserwowalnych elementów, lecz do głębszych praktyk kulturowych. Innymi słowy, powinno się integrować bezpośrednio obserwowalne zdarzenia $\mathrm{z}$ ich wymiarem kulturowym i nie opierać wniosków jedynie na jednym z nich;

- odrzucenie przesadnej wiary w racjonalność ludzkich działań. Badania z zakresu neuronauk społecznych czy kognitywnych wskazują, że człowiekiem kierują głównie procesy nieświadome (np.: emocje, automatyzmy, wyuczone w procesie wychowania wzory, pojęcia i koncepty). Stąd nie należy bezpośrednio zakładać racjonalności zachowania się człowieka;

- wszelkie zjawiska społeczne i biologiczne nie występują tu i teraz, lecz zawsze są bezpośrednio lub pośrednio związane z pewnym procesem (Masters, 1989, s. 130-132; por. van den Berghe, 1991).

Propozycją Mastersa jest systemowe ujęcie człowieka w jego otoczeniu społecznym - wyróżnienie różnych poziomów informacji docierających i wychodzących od człowieka, czyli biologicznego, kulturowego i indywidualnego. Według niego dopiero takie wyróżnienie i interdyscyplinarne badanie zapewnia w miarę pełny obraz zachowania się człowieka. 
W ślad Mastersa poszli również John D. Baldwin i Janice I. Baldwin, którzy wykazali konieczność stworzenia teorii biospołecznych, łączących nauki społeczne z przyrodniczymi, i postulowali nie tylko samą interdyscyplinarność w obrębie badań, lecz nawoływali wręcz do zaangażowania się badaczy nauk społecznych w te międzydyscyplinarne przedsięwzięcia. Powodem tego był fakt, że były one już prowadzone, nawet $\mathrm{z}$ pominięciem socjologów, politologów itd., a prawidłowy tor ( $\mathrm{t}$. niedeterministyczny, niebehawiorystyczny) mogliby im nadać właśnie przedstawiciele tych nauk. Autorzy ci twierdzili, że powinna zostać stworzona teoria biospołeczna, która miałaby trzy założenia:

- powinna być wyważona w tym sensie, że nie byłoby w niej miejsca na dominację czynników biologicznych czy społeczno-kulturowych;

- modele zachowania się uwzględniałyby zarówno kwestie i zagadnienia związane z ewolucją biologiczną, jak i zakorzenienie człowieka i społeczeństw w danej kulturze;

- z każdym badaniem powinno się nadawać odpowiednią rolę czynnikom kulturowym lub biologicznym w zależności od przedmiotu (Baldwin, Baldwin, 1991, s. 476-479).

Powyższe uwagi odnoszą się do całego spektrum neurobiologicznych badań polityki. Co więcej, wydają się być one realizacją tych założeń i propozycji. Neuropolityka nie jest związana ani z determinizmem biologicznym, ani z determinizmem kulturowym. Po pierwsze, koncepcja plastyczności neuronalnej, stojąca u podstaw tego obszaru badawczego, oddala od ostatecznych rozstrzygnięć opartych jedynie na biologii, z drugiej strony narzędzia badawcze pozwalają na empiryczny kontakt z centralnym organem każdego człowieka, jego „czarną skrzynką" - mózgiem, elementem istoty biologicznej.

\section{Narzędzia badawcze neuronauk społecznych}

Siłę napędową (i warunek progowy) badań z zakresu neuroscience stanowi niewątpliwie rozwój narzędzi badawczych. Pierwsze próby zrozumienia anatomiczno-fizjologiczno-funkcjonalnych ludzkich procesów poznawczych, motywacyjnych podejmowane były już w czasach antycznych. Przez wiele wieków prowadzono (w ramach sekcji pośmiertnych) badania anatomiczne. $\mathrm{W}$ wielu przypadkach jako źródło wiedzy traktowano obserwacje żywych ludzi, którzy np. na skutek urazu - doznali uszkodzeń określonych części mózgu (lezje). Ich unieczynnienie, a także zmiany w strukturze osobowości, zachowań pozwalały na wnioskowanie o funkcjach określonych części mózgu. Istotne dla późniejszych badań okazało się odkrycie w XVIII wieku roli impulsów elektrycznych w systemie nerwowym (Luigi Galvani) oraz XIX-wieczne szersze badania anatomiczne odnoszące się do specyfiki funkcjonowania neuronów oraz chemicznych 
połączeń między nimi. W XX wieku co najmniej kilkukrotnie można było obserwować wzrost nadziei na przybliżenie specyfiki działania „czarnej puszki” ludzkiego mózgu. Kluczowe czynniki definiujące użyteczność określonych narzędzi w zakresie obrazowania struktur anatomicznych, aktywności i funkcjonowania mózgu stanowią tu co najmniej cztery kwestie:

- dokładność obrazowania (np. dokładność rejestracji aktywizacji określonych części mózgu), rozdzielczość obrazu (pozwalająca na dokładniejsze obrazowanie badanych struktur) - im większa, tym lepiej;

- czułość czasowa, to jest szybkość obrazowania narzędzia, które warunkują czas między aktywnością mózgu a zdolnością narzędzia do jej rejestracji, zapisu - im wyższa szybkość, tym lepiej;

- możliwość stosowania narzędzia w warunkach, które w największym stopniu zbliżają się do naturalnych, czyli społecznych (duża część narzędzi wymaga stosowania w bardzo specyficznych warunkach, odległych od sytuacji rzeczywistych);

- koszty aparatury badawczej (przyrządów badawczych lub koszty wynajęcia aparatury) - wysokie koszty utrudniają dostęp do badań, zmniejszają możliwości powtórzenia i weryfikacji badań przeprowadzonych przez innych badaczy.

W zakresie oprzyrządowania badawczego neuronauki rozwijały się skokowo, wraz z postępem technicznym. Za istotne należy uznać XX-wieczne wynalazki, stanowiące spektrum narzędziowe neuronauk i podstawy neuroobrazowania mózgu:

- EEG (elektroencefalografia) - to metoda (wynaleziona po I wojnie światowej), która polega na rejestracji zmian potencjału elektrycznego na powierzchni głowy. Zmiany te obrazują elektryczną aktywność neuronalną mózgu. Zazwyczaj dokonywany jest pomiar aktywności elektrycznej $\mathrm{w}$ określonym czasie, przy założonym wpływie badanego bodźca. Zaletą tej metody jest duża czasowa czułość (temporal resolution), szybkość obrazowania zmian w aktywności mózgu lub jego części oraz niski koszt samych narzędzi badawczych. Metoda ta jest wykorzystywana np. po to, aby zbadać odpowiedź mózgu na określone bodźce polityczne (komunikat polityczny, obraz, głos, symbol itp.).

- MEG (magnetoencefalografia) - nieinwazyjna metoda dokonująca pomiaru słabego pola magnetycznego mózgu, związanego z jego elektryczną aktywnością. Ta metoda jest rozwinięciem założeń leżących u podstaw EEG.

- PET (positron emission tomography) - ta metoda zapoczątkowała erę neuroobrazowania funkcjonalnego. Wynaleziona została w latach 60. XX wieku. Metody neuroobrazowania funkcjonalnego wykorzystują fakt, iż aktywne części mózgu wykazują podwyższoną aktywność metaboliczną, która jest zaspokajana przez utlenioną krew. PET jest metodą inwazyjną, 
zakłada przyjęcie przez badanego radioaktywnego izotopu, koniecznego do dalszego obrazowania.

- MRI (structural magnetic resonance imaging) - polega na pomiarze morfologii mózgu, w różnych płaszczyznach, przy wysokiej rozdzielczości 3D. Metoda ta dobrze obrazuje struktury anatomiczne mózgu, które są wykorzystywane np. do wnioskowania komparatystycznego lub badania wpływu określonego bodźca na zmiany anatomiczne. Wadą tej metody są wysokie koszty aparatury, w Polsce liczone w milionach złotych.

- fMRI (functional magnetic resonance imaging) - metoda upowszechniona w latach 90. XX wieku, początek „ery neuronauk”. Tu wnioskowanie o aktywności mózgu opiera się na pomiarze hemodynamicznej aktywności, mierzony sygnał zależy od poziomu utlenienia krwi (blood-oxygen-level dependent - BOLD). Rozwój tego narzędzia badawczego w ogromnym stopniu zdynamizował badania z zakresu neuroscience.

- TMS (transcranial magnetic stimulation) - nieinwazyjna metoda pozwalająca na przezczaszkową stymulację określonych obszarów mózgu (por. Hohol, 2018; Jaśkowski, 2009, s. 42; Haas, 2016, s. 355-370).

Trzeba tu także podkreślić rozwój i doskonalenie narzędzi badawczych stosowanych w neuronauce (Schreiber, 2017, s. 114-131). Rozwój ten jest możliwy nie tylko z powodu zazwyczaj naukowych motywacji (poznawczo-autotelicznych), lecz wynika także ze zbieżności na poziomie narzędzi nauk społecznych i medycznych. Często pierwotne są motywacje medyczne, napędzające i stanowiące racjonalizację kosztów. Współcześnie jednak ogromny wzrost zainteresowania neuronauką spowodował zaangażowanie dużych środków finansowych, programów rządowych i międzyrządowych, niepowiązanych bezpośrednio $\mathrm{z}$ funkcjami medycznymi.

\section{Problem trafności ekologicznej}

Jednym z częstszych zarzutów wobec badań neuroobrazowych i neurofunkcjonalnych jest oderwanie warunków pomiarów od naturalnej, czyli społecznej niszy ekologicznej. PET i fMRI zakładają pomiary u badanego, który przebywa w środku aparatury pomiarowej, ich użyteczność, podobieństwo do realnych warunków są mocno ograniczone. Nie jest to przeszkodą przy badaniach medycznych, jednak tam, gdzie badane są neurobiologiczne podstawy procesów umysłowych, odnoszących się do realnych zjawisk, sytuacji społeczno-politycznych, przebywanie $\mathrm{w}$,tubie” rezonansu magnetycznego tworzy środowisko niepodobne do realiów. Lepiej pod tym względem prezentuje się np. spektroskopia bliskiej podczerwieni (near infrared spectroscopy - NIRS), która polega na przepuszczaniu przez czaszkę słabych promieni lasera, fali świetlnej i pomiarach 
poziomu utlenienia krwi. Pozwala ona na warunki bliższe rzeczywistości społecznej. Pomocne będą tu także inne metody obrazowania aktywności mózgu „na odległość", np. optyczne określenie aktywności neuronalnej (event-related optical signal - EROS) (Gratton, 2010). Dalsze doskonalenie metod badawczych w tym zakresie umożliwi bliższe rzeczywistości obrazowanie aktywności mózgu.

\section{Główne kierunki badań neuropolitycznych}

Współczesne neuronauki społeczne stawiają sobie za cel prześledzenie (na miarę dostępnych narzędzi) powiązań na linii: mózg (jako organ biologiczny) i umysł (jako konstrukt psychologiczno-społeczny). Jeszcze w latach 80. XX wieku popularna była (np. w kognitywistyce) metafora procesów psychologicznych człowieka na podobieństwo działania komputera. W tym ostatnim można wyróżnić dwie płaszczyzny: hardware (sprzęt komputerowy) i software (oprogramowanie). Funkcjonalna całość sprzętowa i programowa miała odpowiadać sferze biologicznej (mózg) i psychicznej (umysł) u człowieka. Współcześnie tego rodzaju metafory nie mogą być traktowane dosłownie. Neuronauki badają charakter zależności między mózgiem biologicznym a umysłem w dwóch kierunkach (sprzężenie zwrotne):

- wpływu warstwy biologicznej, neurofizjologicznej na charakter procesów psychicznych, poznawczych, decyzyjnych itp. To wpływ „od dołu do góry”, od składnika biologicznego do składnika psychicznego (bottom - up);

- wpływu stanów umysłowych na warstwę biologiczną; to wpływ „od góry do dołu" (top - down) (Rose, Abi-Rached, 2014, s. 3-23).

Pierwszy wymiar jest oczywisty, tu pytania idą w kierunku określenia, w jakim zakresie, w jaki sposób i z jakim skutkiem mózg biologiczny współdeterminuje stany psychologiczne, procesy poznawcze, decyzyjne, motywuje zachowania itp. Rozwój narzędzi badawczych pozwala na coraz dokładniejsze i bardziej wyrafinowane dookreślenie tego kierunku zależności. Drugi wymiar jest mniej oczywisty, lecz także niezaskakujący. Tu zakłada się, iż przeżycia, doświadczenia, stany psychiczne kształtują w pewnych granicach warstwę anatomiczną i fizjologiczną (neuroplastyczność mózgu), np. długotrwała gra na instrumencie muzycznym skutkuje rozwojem określonych części mózgu, aktywność intelektualna „konserwuje" pamięć itp. Ten kierunek badań pozwala dookreślić, czy i w jakim zakresie określony tryb aktywności będzie skutkował zmianami anatomiczno-fizjologicznymi mózgu. W takim przypadku „software” zmienia, kształtuje „hardware”. 


\section{Pole przedmiotowe neuropolityki}

Zakres zainteresowań przedmiotowych neuronauk politycznych trudno uznać za szczególnie rozszerzający pole badań nauk o polityce. Stawiane są tu problemy od dekad interesujące politologów, takie jak: zachowania polityczne, procesy podejmowania decyzji politycznych, orientacje/postawy polityczne itp. Stąd często - w kontekście neuroanatomicznym i neurofizjologicznym - pojawiają się takie problemy jak:

- charakter różnic anatomiczno-fizjologicznych między wyróżnionymi kategoriami analitycznymi, np. konserwatyści - liberałowie (Jost et al., 2014, s. 16 i n.; Westen et al., 2006; Schreiber et al., 2013);

- przebieg procesów poznawczych, aktywizujących określone części mózgu, o określonych, znanych (w znacznym stopniu) funkcjach umysłowych (Jost et al., 2014, s. 24 i n.);

- charakter reakcji, sposobu aktywizacji określonych części mózgu pod wpływem prezentowanych bodźców. To podejście jest znane jak ROI (region of interest), polega na obrazowaniu określonych aktywności mózgu pod wpływem aplikowanych bodźców (Schreiber, 2017, s. 123 i n.), np. obrazów kandydatów politycznych, określonych sytuacji o charakterze dylematu do rozstrzygnięcia (Liu, Jing, Gao, 2015, s. 143; Kaplan, Freedman, Iacoboni, 2007);

- zakres aktywności mózgu w czasie umysłowego podejmowania decyzji politycznych;

- charakter aktywności mózgu w zakresie aktywizacji wartości politycznych/ideologicznych (Sardamov, 2007, s. 407-424);

- przetwarzanie treści, komunikatów, informacji politycznych (Westen et al., 2006) i inne.

W tym zakresie neuropolitykę trudno uznać za rewolucyjną. Tym, co napędza jej dynamiczny rozwój, nie jest zatem przedmiot badań, lecz podejście, jak na te pytania odpowiadać. Polityczne neuronauki zakładają próbę opisu, wyjaśnienia i w pewnym zakresie predykcję motywacji i zachowań politycznych „przez mózg” (Altermark, Nyberg, 2018, s. 31-48): jego struktury anatomiczno-funkcjonalne, uaktywnianie jego części, neurochemiczny charakter procesów umysłowych, wykorzystywane połączenia, neuronalne ścieżki poznawcze, pamięciowe, decyzyjne w tym złożonym organie. Wyjaśnianie „przez mózg” nie powinno być w żadnym zakresie uznawane za alternatywne wobec dotychczasowych modeli poznawczo-wyjaśniających stosowanych w naukach o polityce. To ich uzupełnienie, spojrzenie z nowej perspektywy, na innej płaszczyźnie, lub co najmniej z perspektywy nowych narzędzi badawczych. 


\section{Przykłady badań z zakresu neuropolityki}

Jako przykład badań podstawowych i stosowanych można uznać studium wykonane przez zespół badaczy w październiku 2004 roku, w przededniu wyborów prezydenckich w USA (Westen et al., 2006). Badaną grupę 50 osób stanowili zwolennicy George'a W. Busha i Johna Kerry'ego. Wykorzystano tu metodę fMRI - funkcjonalnego rezonansu magnetycznego. Badani oceniali w skali: „całkowicie się zgadzam - całkowicie się nie zgadzam” twierdzenia wzmacniające ich postawy polityczne oraz takie, które wymagały zanegowania, aktywności zmierzającej do ich odrzucenia, a także twierdzenia neutralne. Funkcjonalny rezonans obrazował, które części mózgu badanych wykazywały dużą aktywność przy reakcji na twierdzenia zgodne $\mathrm{z}$ orientacją partyjną badanego, a które w wyniku konfrontacji z twierdzeniami przeciwnego obozu politycznego. Badania prowadziły do wniosków w zakresie aktywizacji regionalnej (ROI) mózgu pod wpływem treści politycznych oraz różnic $\mathrm{w}$ tym zakresie, gdy badany był skonfrontowany $\mathrm{z}$ treściami zgodnymi z jego orientacją partyjną lub treściami charakterystycznymi dla obozu przeciwników politycznych. W zależności od przypadku aktywizowane były ośrodki odpowiedzialne za procesy emocjonalne lub racjonalne. Możliwe były także do zauważenia różnice w zakresie aktywności określonych części mózgu między osobami o orientacji demokratycznej i republikańskiej, a także różnice międzypłciowe. Badania takie pozwalają nie tylko na pogłębienie wiedzy w płaszczyźnie zrozumienia procesów poznawczych, motywacyjnych, decyzyjnych oraz różnic fizjologicznych między badanymi o różnych orientacjach politycznych. Można z nich również czerpać użyteczne wnioski w zakresie określenia, jaki charakter komunikatów, treści politycznych będzie skuteczniejszy w odniesieniu do swoich zwolenników, a jaki w stosunku do elektoratu rywali (neuromarketing).

David Amodio wraz ze współpracownikami przeprowadzili badanie, którego celem było zbadanie, czy ideologia polityczna wpływa na poznanie, czy reprezentowanie takiego lub innego poglądu ma swoje przełożenie na aktywność mózgu, oraz weryfikacja tezy dotyczącej mechanizmu monitorowania konfliktu, kwestii reakcji (nawykowej) na konkretną sytuację (mechanizm powiązany $\mathrm{z}$ przednią korą zakrętu obręczy [ACC]). W tym celu użyto funkcjonalnego rezonansu magnetycznego oraz elektroencefalografu. Po teście dotyczącym poglądów politycznych badanym nakazano wykonać zadanie Go/No-Go. Musieli oni jak najszybciej zareagować na bodziec Go, przy czym był on tak częsty, że reakcja stawała się nawykowa. Wówczas pojawiał się No-Go, wymuszający inną reakcję. Wyniki wykazały korelację między prawidłową reakcją na bodźce (zarówno Go, jak i No-Go), orientacją polityczną a aktywnością ACC. Osoby identyfikujące się jako liberałowie zdecydowanie częściej prawidłowo reagowały i dostrzegały konflikt dotyczący bodźców (a zatem są bardziej skłonne do zachowań alternatywnych wobec stałych bodźców), dostrzeżono również u nich 
większą aktywność ACC; przy czym konserwatyści - im bardziej skrajni na skali konserwatyzm - liberalizm, tym mniej byli wyczuleni na neurokognitywne reakcje na konflikt (Amodio, Jost, Master, Yee, 2007). Warto wspomnieć, że procedura została powtórzona przez innych badaczy i wykazała bardzo podobne wyniki, z tym że uzupełniono ją o dodatkowy test na linii tradycjonalizm - egalitaryzm (Choma, Dywan, Segalowitz, Van Noordt, Weissflog, 2013).

W innym, bardziej ogólnym, badaniu Ryota Kanai i jego współpracownicy podjęli próbę odnalezienia funkcjonalnych oraz strukturalnych różnic w mózgu między konserwatystami a liberałami, m.in. na kanwie powyższego testu, wykonanego przez Amodia i innych (Feilden, Firth, Kanai, Rees, 2011). Tutaj zastosowano rezonans magnetyczny (MRI) oraz morfometrię opartą na wokselach (VBM). Podobnie jak powyżej, badani musieli wykonać najpierw test postaw politycznych, po czym przystąpiono do stosowania narzędzi badawczych. Wyniki wykazały, że u osób, które identyfikowały się jako liberalne, widoczna była zwiększona objętość substancji szarej wokół ACC, co potwierdziło badanie przeprowadzone przez Amodia i innych. W przypadku osób deklarujących konserwatyzm dostrzeżono większą objętość substancji szarej wokół ciała migdałowatego, które odpowiada m.in. za reakcje emocjonalne lub instynktowne (walcz lub uciekaj). W innym miejscu odnoszono tę cechę konserwatystów do „teorii uzasadniania systemu”, która głosi, że ludzie chcą utrzymać obecny system ze względu na potrzeby psychologiczne, np. pewności i porządku (Jost et al., 2014, s. 22-23). Warto dodać, że badanie powtórzono na innej grupie badanych i otrzymano podobne wyniki.

Powyższe badania są istotne nie tylko dlatego, że identyfikują części mózgu, które wykazują większą aktywność (fizjologia), objętość (anatomia) w przypadku takiej czy innej orientacji politycznej. Pozwalają one także pogłębić wiedzę dotyczącą neurokognitywnych oraz psychologicznych elementów postrzegania rzeczywistości przez reprezentantów różnych ideologii oraz zrozumieć rolę automatyzmów w ocenie rzeczywistości politycznej, które mają swoją głębszą przyczynę (w kierunku: ideologia á mózg á umysł á ocena, na co zwracają uwagę sami autorzy tychże badań) o podłożu neuronalnym, nieświadomym, na linii mózg - umysł.

\section{Perspektywy dla neuronauki: nadzieje i miraże}

Neuropolityka jest jednym $\mathrm{z}$ dynamicznie rozwijających się kierunków badań politologicznych. Mimo iż wyrasta z nauk przyrodniczych, nie ma cech determinizmu biologicznego czy prostego behawioralizmu, zwraca się w stronę zlikwidowania linii demarkacyjnej dzielącej naturę i kulturę poprzez uwzględnienie ich sprzężenia zwrotnego, np. w ramach koncepcji plastyczności neuronalnej. 
Dotychczasowy rozwój neuronauk jest imponujący. Przy wykorzystaniu dużych środków finansowych i nowoczesnej aparatury badawczej neurologiczny aspekt badań społecznych zyskał nowy wymiar. W pewnym zakresie dotyczy to także rozważań o polityce. Dynamika włączania tego podejścia do wybranych fragmentów nauk o polityce z pewnością nie pozwala na jego zignorowanie. Taki entuzjazm może jednak być szkodliwy. Pytań i nadziei może być dużo więcej niż możliwości. Trzeba $\mathrm{w}$ pełni zdawać sobie sprawę z ograniczeń samego podejścia (na poziomie ontologicznym i epistemologicznym), jak i z ograniczeń samej aparatury badawczej. Neurobiolodzy w najbliższej przyszłości (raczej) nie zastąpią jeszcze politologów. Badania politologiczne wciąż powinny być oparte na aspektach interpretacyjnych i krytycznych, takich jak ujmowanie zjawisk w ich historyczności, w ich uwikłaniu w wartości, kulturę, mechanizmy, władzę, słowem - w kontekście, w którego ramach fenomeny pojawiają się i funkcjonują.

Równie istotne dla środowiska politologów jest jednak „nieprzespanie” badań z zakresu neuroscience. Mimo iż możliwości współczesnych neuronauk stanowią tylko niewielki wycinek pola przedmiotowego nauk o polityce, to jednak rozszerzają owo pole, dostarczają integracyjnego podejścia i użytecznych narzędzi badawczych (tak w zakresie badań podstawowych, jak i stosowanych). Współczesne neuronauki skutecznie bronią się przed zarzutami o determinizm biologiczny czy zredukowanie złożoności procesów umysłowych do warstwy biochemii, fizjologii, anatomii mózgu. Jednak tych ostatnich nie sposób zignorować. Stanowią one istotny element (bazę), poziom przeżyć i stanów psychicznych. Rozwój neuronauk stanowi szansę dla politologów, którzy zyskują kolejną płaszczyznę poszukiwania odpowiedzi na nurtujące ich pytania. Jest to jednak także wyzwanie. Pole politologicznych badań jest w coraz większym stopniu infiltrowane przez badaczy daleko spoza „rodziny”. Taka jest jednak nauka. Nie ma tu domen, zastrzeżonych pól badawczych, wyłączności dyscyplinarnych, zamkniętego katalogu narzędzi badawczych. Sensowne wydaje się raczej poszukanie zastosowania i użyteczności dla politologów w nowych kierunkach badawczych, nowych narzędziach. Warto pamiętać, że nauki o polityce, a w tym badania $w$ ramach teorii polityki, ze względu na przedmiot swoich zainteresowań, czerpią i syntetyzują wiedzę z innych dyscyplin. W zakresie neuropolityki politolog mógłby pełnić funkcję integrującą różne podejścia, różne dyscypliny. Czy tak się stanie, pokaże przyszłość.

\section{Literatura}

Altermark, N., Nyberg, L. (2018). „Neuro-Problems: Knowing Politics Through the Brain”. Culture Unbound, Vol. 10, Issue 1, s. 31-48.

Amodio, D., Jost, J., Master, S., Yee, C. (2007). „Neurocognitive Correlates of Liberalism and Conservatism". Nature Neuroscience, 10(10), s. 1246-1247. 
Anderson, S.W., Bechara, A., Damasio, H., Damasio, A., Tranel, D. (2005). „Impairment of Social and Moral Behavior Related to Early Damage in Human Prefrontal Cortex". W: J. Cacioppo, G. Berntson (eds.). Social Neuroscience: Key Readings. New York-Hove: Psychology Press.

Baldwin, J.D., Baldwin, J.I. (1991). „Socjobiologia czy wyważona teoria biospołeczna?”. W: B. Szacka, J. Szacki (red.). Człowiek, zwierzę społeczne. Warszawa: Czytelnik.

Blank, R. (2013). Intervention in the Brain: Politics, Policy, and Ethics. Cambridge-London: The MIT Press.

Cacioppo, J., Berntson, G. (2005). „Preface”. W: J. Cacioppo, G. Berntson (eds.). Social Neuroscience: Key Readings. New York-Hove: Psychology Press.

Cacioppo, J., Visser, P. (2003). „Political Psychology and Social Neuroscience: Strange Bedfellows or Comrades in Arms?". Political Psychology, 24(4), s. 647-656.

Capra, F. (1983). The Turning Point: Science, Society, and the Rising Culture. New York: Bantam.

Choma, B., Dywan, J., Segalowitz, S., Van Noordt, R., Weissflog, M. (2013). „The Political (and Physiological) Divide: Political Orientation, Performance Monitoring, and the Anterior Cingulate Response”. Social Neuroscience, 8(5), s. 434-447.

Connolly, W.E. (2002). Neuropolitics: Thinking, Culture, Speed, Vol. 23. MinneapolisLondon: University of Minnesota Press.

Damasio, A. (1994). Descartes' Error: Emotion, Reason and the Human Brain. New York: Avon Books.

Damasio, H., Damasio, A., Frank, R., Grabowski, T., Galaburda, A. (2005). „The Return of Phineas Gage: Clues about the Brain from the Skull of a Famous Patient”. W: J. Cacioppo, G. Berntson (eds.), Social Neuroscience: Key Readings. New YorkHove: Psychology Press.

Feilden, T., Firth, C., Kanai, R., Rees, G. (2011). „Political Orientations Are Correlated with Brain Structure in Young Adults”. Current Biology, 21(8), s. 677-680.

Gratton, M.F.G. (2010). „Fast Optical Imaging of Human Brain Function”. Frontiers in Human Neuroscience, 4.

Haas, I.J. (2016). „Political Neuroscience”. W: J. Abshner, J. Cloutier (eds.), Neuroimaging Personality, Social Cognition, and Character. Amsterdam et al.: Academic Press, s. $355-370$.

Hohol, M. (2018). „Podstawy neuronauki poznawczej”. W: B. Brożek, Ł. Kurek, J. Stelmach (red.). Prawo i nauki kognitywne. Warszawa: Wolters Kluwer.

Jaśkowski, P. (2009). Neuronauka poznawcza. Warszawa: Vizja Press.

Jost, J.T. et al. (2014). „Political Neuroscience: The Beginning of a Beautiful Friendship”. Advances in Political Psychology, Vol. 35, Suppl. 1, s. 3-42.

Kaplan, J.T., Freedman, J., Iacoboni, M. (2007). „Us versus Them: Political Attitudes and Party Affiliation Influence Neural Response to Faces of Presidential Candidates". Neuropsychologia, 45(1), s. 55-64.

Lakoff, G. (2009). The Political Mind: A Cognitive Scientist's Guide to Your Brain and its Politics. New York: Penguin Books.

Lemke, T. (2010). Biopolityka. Warszawa: Wydawnictwo „Sic!”.

Liu, Y., Jing, Y., Gao, M. (2015). „Transformational Leadership: From the Perspective of Neurological Leadership". Open Journal of Leadership, 4(04), s. 143-152.

Masters, R. (1989). The Nature of Politics. New Haven-London: Yale University Press. 
Rose, N., Abi-Rached, J. (2014). „Governing through the Brain: Neuropolitics, Neuroscience and Subjectivity". The Cambridge Journal of Anthropology, 32(1), s. 3-23.

Sardamov, I. (2007). „Burnt into the Brain: Towards a Redefinition of Political Culture”. Democratisation, 14(3), s. 407-424.

Schreiber, D. (2011). „From Scan to Neuropolitics”. W: P. Hatemi, R. McDermott (eds.). Man Is by Nature a Political Animal: Evolution, Biology, and Politics. Chicago-London: The University of Chicago Press.

Schreiber, D. (2017). „Neuropolitics: Twenty Years Later”. Politics and the Life Sciences, 36(2), s. 114-131.

Schreiber, D. et al. (2013). „Red Brain, Blue Brain: Evaluative Processes Differ in Democrats and Republicans". PLoS One, 8(2).

Van den Berghe, P.L. (1991). „Łączenie paradygmatów: biologia i nauki społeczne”. W: B. Szacka, J. Szacki (red.). Człowiek, zwierzę społeczne. Warszawa: Czytelnik.

Westen et al. (2006). „Neural Bases of Motivated Reasoning: An fMRI Study of Emotional Constraints on Partisan Political Judgment in the 2004 US Presidential Election". Journal of Cognitive Neuroscience, 18(11), s. 1947-1958.

\section{Streszczenie}

Neuropolityka to interdyscyplinarny obszar badań, znajdujący się na przecięciu nauk, łączący nauki polityczne z neuronaukami. Nie jest to jednak kolejny kierunek, który zakłada determinizm biologiczny. Opiera się na przekonaniu o przenikaniu się natury i kultury w człowieku, warstwy cielesnej i umysłowej. Celem artykułu jest przybliżenie czytelnikowi historycznych i teoretycznych aspektów tego wciąż rozwijającego się obszaru badawczego. Naszkicowane zostały również narzędzia badawcze oraz główne kierunki badań neuropolitycznych. Autorzy wskazują na pozytywne, jak i negatywne skutki płynące z badań neuropolitycznych oraz prezentują perspektywy stojące przed naukami o polityce i neuronaukami.

Słowa kluczowe: neuropolityka, nauki o polityce, neuronauki społeczne, biopolityka, natura, kultura, biologia 